\title{
LA MUJER MORISCA O ESCLAVA BLANCA EN EL PERÚ DEL SIGLO XVI
}

Jaime Cáceres Enríquez²

Las influencias moriscas en el Perú, que se advierten en diversas expresiones culturales, datan del siglo XVI y son perceptibles hasta hoy en día.

¿Cómo llegó esa influencia que entraña rasgos árabes e islámicos? Para encontrar la o las vertientes que canalizaron esta presencia cultural es preciso situarnos en el contexto de la historia del siglo XVI que, aunque conocida, es conveniente recordar. Los dos hechos históricos con que se inicia esa centuria corresponden al final de la Reconquista española, que determina una nueva estructura política, religiosa, económica y social en la Península Ibérica, con el desplazamiento del poder árabe, y el Descubrimiento o Encuentro de Mundos en América.

La empresa del Descubrimiento, e inmediatamente después la de la Colonización, estaban impregnadas del carácter de aventura y por ende de riesgos. La Corona española no podía, en ese momento crucial de su historia, descuidar detalle alguno que pudiese atentar a sus intereses: el acceso a nuevas vías de comunicación, la posesión de tierras y la explotación de sus riquezas, y la labor evangelizadora para la difusión de la fe cristiana.

Dentro del mismo contexto histórico se encuentra la problemática mora. La Toma de Granada, que por coincidencia ocurre el mismo año de 1492 en el que se produce el encuentro de América, está llena de sucesos que revolucionan el sistema de vida prevalente por casi ocho siglos en Andalucía. Estas transformaciones comprenden, a grandes rasgos, una serie de hechos que van desde la pérdida del poder político y militar, materializa-

1. Ponencia presentada por el autor de este artículo en las V Jornadas sobre el Inca Garcilaso y el Mestizaje en Indias, Montilla, 1994.

2. Investigador del tema morisco en el Perú en el siglo XVI. Miembro del Grupo de Estudio ACALAPI de la UNESCO. Graduado en historia, Universidad Nacional Mayor de San Marcos en Lima. Diplomático peruano. 
do con el traslado al Norte de Africa de Boabdil y su Corte en 1492, hasta la expulsión de los moriscos en 1609. Indudablemente el período señalado corresponde en América a los momentos del Descubrimiento, inicio de la Colonización y asentamiento del poder español en el Nuevo Mundo.

La extinción del poder moro no significó la desaparición de la población árabe musulmana asentada en el sur de España, la misma que sin embargo debía enfrentar un sistema de vida diferente: el de la administración cristiana. Las cláusulas de la Capitulación de Granada contemplaban ciertas garantías para los moros, basadas en una incipiente tolerancia. Ésta duró poco, pues junto a un nuevo régimen de propiedad y de privilegios se estableció la campaña de evangelización forzada que determinó por un lado un número creciente de moriscos o moros conversos (cristianos falsos) y la institucionalización de la intolerancia religiosa a través de la persecución y la Inquisición. Como resultado de esta situación represiva aparece la resistencia armada en las Alpujarras, la constitución de estratégicos reductos como el del virulento Hornachos y el desplazamiento de moriscos a diversos lugares dentro de España, que podían ofrecer mayores garantías, o fuera de ésta en otros países de Europa o al Norte de Africa de sus orígenes. Los itinerarios de estas migraciones de moriscos antes y después de la expulsión han sido prolijamente estudiados por el profesor Míkel de Epalza ${ }^{3}$.

Queda sin embargo probar si los moriscos llegaron a América. Ciertas evidencias nos anticipan la posibilidad de que lo hicieron. En primer lugar las Provisiones Reales emitidas desde el primer viaje de Colón contienen explícitas prohibiciones para el paso a Indias de moriscos. Pese a ello se tienen datos de que inclusive en la primera expedición de Colón, el primero que avista tierra, Rodrigo de Triana, era un morisco, según lo refiere don Salvador Gómez Nogales en su estudio sobre este personaje $e^{4}$.

Como hemos señalado anteriormente, los riesgos de la aventura en el Nuevo Mundo dificultaban el enrolamiento de tripulantes. A ello debemos añadir, con un alto margen de probabilidad, la presencia en los puertos de moriscos deseosos de escapar de la intolerancia. Presentábase pues una situación ambigua: el Rey de España no estaba dispuesto a permitir que la empresa cristiana fuese desviada por la presencia de infiltraciones islámicas, y sin embargo requeríase, sobre todo en el primer momento de la Conquista, de mano de obra que en forma abundante la ofrecían los moros. La fórmula para conciliar esta duplicidad sería la de expedir permisos especiales para llevar a

3. Catedrático titular de la Universidad de Alicante, Departamento de Estudios Arabes e Islámicos, especialista en el tema de moriscos. Ver Míkel DE EPALZA, Los moriscos antes y después de la expulsión, Madrid, 1992 y 1994 (2"ed.) y Míkel DE EPALZA (ed.), L'expulsió dels moriscos: conseqiiències en el món islàmic y en el món cristiá, Barcelona, 1994.

4. Los datos de este estudio preparado por el profesor español Salvador Gómez Nogales se encuentran en la biblioteca "Félix Pareja", del Instituto de Cooperación con el Mundo Arabe, de Madrid. 
Indias moriscos, mediante Reales Cédulas firmadas por el propio Rey, como un medio de control, y la formalización ante escribanos públicos de contratos de soldada mediante lo cual se legalizaba la posesión de esclavos, incluyendo los de origen moro. Aparte de ello no cabe duda de que los moriscos llegaron a América con nombres y apellidos cristianos, hecho que para la investigación histórica actual es un serio obstáculo para el reconocimiento del origen moro. De esta manera, por ejemplo, en los documentos, contratos, planos, etc., de construcción de edificios donde es evidente la arquitectura morisca, resulta imposible identificar en la relación de artesanos el origen moro de ellos. Se dice con razón que esta dificultad podría ser obviada solamente si estuviésemos frente al personaje para reconocer sus rasgos físicos y sobre todo su acento al hablar; lo cual es definitivamente inalcanzable.

Hemos hablado de las vertientes que canalizaron el trasvase de la cultura árabe islámica al Perú, resultando paradógicamente que la España cristiana es un factor importante en este fenómeno y que el elemento propiamente moro es altamente complicado identificarlo por las razones expuestas. Sin embargo, todo este preámbulo sirva para presentar el caso de la mujer morisca o esclava blanca que, en forma más abierta y pese a su condición de conversa a la fuerza, prefirió llegar al Nuevo Mundo como esclava blanca a fin de no perder su identidad de origen y participar de manera legal en América.

\section{LA MORISCA O ESCLAVA BLANCA}

"La escasez de mujeres españolas en los primeros tiempos hizo indispensable para los varones europeos la presencia de las mujeres andinas". Así lo expresa María Rostoworoski ${ }^{5}$. A ello habría que añadir que este hecho también generó la importación de esclavas blancas. James Lockhart ${ }^{6}$ nos informa a este respecto que muchas esclavas blancas habían pasado a América, en particular a Nueva España, entre 1506 y 1527.

Las uniones con las indias peruanas, que se producían en gran cantidad, significaron no sólo el riesgo de mezclarse con una raza desconocida, sino también, aunque ellas fuesen de noble estirpe, casarse con una idólatra

5. Ver la historiadora peruana María Rostoworoski de Díez CANedo, Doña Francisca Pizarro, una ilustre mestiza. 1534-1598, Lima, Instituto de Estudios Peruanos Ediciones (Horacio Urteaga 694, Lima 11), 1989: "La escasez de mujeres españolas en los primeros tiempos hizo indispensable para los varones europeos la presencia de las mujeres indias", p. 15.

6. Ver el historiador norteamericano James LOCKHART, El mundo hispano-peruano. 1532-1560, México, Fondo de Cultura Económica, 1952 (traducción de Mariana Mould): "Muchas esclavas blancas habían pasado a América y ellas participaron en la verdadera Conquista del Perú de 1532 a 1535" (el texto original en inglés difiere un tanto en la redacción del texto traducido al castellano). 
de reciente e incipiente conversión, sin mencionar los riesgos de salud de uno y otro lado.

Estamos hablando del siglo XVI y en particular de las primeras décadas de la colonización en el Perú. Por ello cuando Louis Cardaillac ${ }^{7}$ advierte un problema de vocabulario, fuente de malentendidos, refiriéndose a la palabra "morisco", dice que a fines del siglo XVII el término "morisco" había tomado en Indias un sentido totalmente diferente del que había tomado en España, pues designaba al hijo de un español y de una mestiza mulata, un individuo nacido con tres cuartas partes de sangre blanca y un cuarto de sangre negra.

Esta advertencia no tiene vigencia para los documentos peruanos del siglo XVI, como pueden ser las menciones de moriscas y moriscos en partidas bautismales de 1538 a 1548 o en actos notariales de 1550 a 1560. En dichos años el término "morisco" o el de "esclava blanca" correspondía, en el Perú, al mismo sentido con que se aplicaba en España. La advertencia de Cardaillac es pertinente a fines del siglo XVII, según él mismo lo indica, y corresponde sobre todo a un mal uso generalizado de dicha palabra en México, al punto de existir disposiciones reales para enmendar este error.

En el siglo XVII existen a este respecto tablas de castas y mestizajes que señalan el término "morisco" como el resultado de una mezcla de razas, muy diferente a la acepción que conocemos como origen de la palabra moro y como el uso del término "morisco", materia de este trabajo.

En todo caso no cabe confusión cuando en la primera época de la Conquista peruana fueron evidentes la presencia directa de ellas y ellos, y cuando la mezcla de razas y el proceso de mestizaje se producirían años más tarde.

Lockhart ${ }^{8}$ trae dos consideraciones igualmente importantes:

a) Así como en el comercio de esclavos negros el número de hombres era muy superior al de las mujeres, en el caso de los esclavos moros, el número de mujeres fue muy superior al de hombres.

b) El papel que juega la mujer mora, como hemos visto, corresponde a la primera época de la colonización, pero decrece conforme van llegando las mujeres españolas. Las moras vuelven a España antes de concluir el siglo XVI, lo hacen en condiciones superadas y ya no regresan a América, dejando, sin embargo, y a pesar de corresponderles un período relativamente corto, trazos culturales acentuados gracias a su presencia física y a su definida personalidad.

7. Louis Cardaillac (dir.), Les Morisques et l'Inquisition, Paris, Publisud, 1990, Chapitre «Les tribunaux des Iles et d'Outre Mer», p. 330.

8. J. LOCKHART, op. cit., pp. 251-252. 
Podemos decir pues que, en la época a que nos estamos refiriendo, eran muy pocas las damas españolas que vinieron al Perú. En la década de 1570 se sabe que doña Isabel Rodríguez solía agregar a sus títulos: "La Conquistadora, primera en estos Reynos del Perú". Diego de Trujillo anota que en 1537 había en Lima 380 españoles y tan sólo 14 mujeres españolas.

Raúl Porras Barrenechea, basándose en el mismo testimonio de Diego de Trujillo, menciona que con Hernando de Soto llegó la primera mujer española que vino a este Reyno, que se llamaban Juana Hernández; sin embargo doña Inés Muñoz reclamaba ser la primera mujer casada que entró al Perú. Existen otros testimonios sobre la primera doncella noble española que entró a Lima, doña Inés Bravo de Lagunas9.

James Lockhart ${ }^{10}$ asegura que entre 1532 y 1549 vinieron al Perú por lo menos unas 300 mujeres calificadas de moriscas. En cautiverio, es cierto, pero pronto mezclaron su sangre adquiriendo plena libertad, tanto que llegaron a contribuir decisivamente al proceso del surgimiento del criollismo al unirse a conquistadores de valía y a destacados funcionarios del inicio de la Colonia. De esta manera transmitieron su cultura dejando un legado árabe visible en numerosos aspectos, y en especial dentro de la limeñidad.

El análisis de los documentos del siglo XVI nos lleva a ciertas conclusiones. En primer lugar se advierte que conforme avanza el siglo van decreciendo las inscripciones en los registros parroquiales, notariales y otros, de moriscos y moriscas. Se podría también señalar que a mediados del siglo figuran solamente los moriscos, aceptados plenamente por su posición social y económica innegables; tales son los casos de Cristóbal de Burgos ${ }^{11}$ y de Beatriz Salcedo ${ }^{12}$. En cambio la presencia de negros es constante y la ausencia de judaizantes es total.

Conviene igualmente repasar la política de la Corona respecto a aquellos españoles que se trasladaron al Perú solteros o sin llevar sus esposas. La

9. Este párrafo y el precedente están extraídos de la obra Una relación inédita de la Conquista, la Crónica de Diego de Trujillo (Miraflores, Lima, Editorial Minerva, 1970, p. 90), del historiador peruano Raúl Porras Barrenechea.

10. J. LOCKHART, op. cit., pp. 251-252.

11. Carmen BERNARD et Serge GRUZINSKI, Histoire du Nouveau Monde 1492-1550, Centre National des Lettres: "Cristóbal de Burgos, nacido en 1500, fue esclavo de una dama de Burgos. Acompaña a D. Francisco Pizarro en la mayoría de sus campañas. Llegó a enriquecerse de tal manera en el Perú que pudo comprar su libertad. Es nombrado Regidor Perpetuo de Lima, cargo al que no podía pertenecer ningún morisco", página 484. Datos tomados del Tomo II, libro II, p. 372 de Gutiérrez de Santa Clara (1963).

12. Beatriz de Salcedo, morisca, llega al Perú en 1532 como esclava blanca del Veedor Real o Contralor García de Salcedo, con quien se casa. Expediente de dote, Archivo General de la Nación del Perú y Escrituras de traspaso de bienes a favor de Beatriz de Salcedo, 20 de febrero de 1562 (Notario Esteban Pérez, Protocolo 127, folios 164 a 169) y Archivo General de Indias, Sevilla, "Información de Servicios Beatriz de Salcedo 1562", Expediente Lima 118, legajo 3840 . 
ausencia de ellas es evidente en la primera época de la Conquista. Ello explica las específicas Reales Cédulas propiciando la presencia de la mujer española en el Perú. De esta manera el Rey ordenaba se les diese preferencia en la concesión de beneficios a los casados con españolas. Igualmente encontramos numerosas Reales Cédulas otorgando permisos para viajar a España a aquellos que volvían con el propósito de casarse y regresar a Indias ${ }^{13}$.

Otra evidencia nos la proporciona Enrique Otte al publicar numerosas misivas remitidas desde Indias cuyos destinatarios más frecuentes eran las esposas y también las mujeres de las cuales estaban enamorados los emigrantes 14 .

Pasemos ahora a sustentar con documentos la presencia de la mujer morisca.

Por Real Cédula de 21 de mayo de 1534, el Rey faculta al capitán Hernando Pizarro llevar al Perú cuatro esclavas blancas para servicio de Francisco Pizarro, su hermano, Gobernador de la Provincia del Perú, firmada en la ciudad de Toledo ${ }^{15}$.

En la Gobernación del Perú existen además otros testimonios sobre la presencia de esclavas blancas. En junio de 1537 se registran dos hechos significativos: uno es la compra de una esclava blanca por Juan de Vallejo, que tenía concubina india e hijo en ella, por la que paga 1.200 castellanos. Otro es un acto público notarial mediante el cual López de Idiáquez otorga carta de libertad a favor de Beatriz, su esclava blanca herrada en la barba, "por los buenos servicios que le ha prestado"16.

La inclinación del conquistador español por la mujer mora, que determina, entre otras cosas, el pedido de los Pizarro para importar cuatro escla-

13. Ver el historiador peruano Raúl PORRAS BARRENECHEA, Cedulario del Perí (Siglos XVI, XVII y XVIII), Lima, Departamento de Relaciones Culturales del Ministerio de Relaciones Exteriores del Perú, 1948, Tomo II (1534-1538)

Algunas citas: p. 122, Real Cédula instando para que los casados sean preferidos en los Repartimientos (1535); p. 123, para que lleven sus mugeres; p 117, licencia a Pedro de Candia para que venga a estos Reynos; pp. 230-231, licencia a Francisco Núñez por dos años para venir a estos Reynos a se casar y llevar a esa tierra a su muger y casa para bibir y permanecer en ella; p. 177, instrucción general al Obispo y Cedula al Governador para que los casados que oviere cinco años que están en aquella tierra lleven sus mugeres o se vengan a hazer vida con ellas, licencias idem; p. 171 a Gregorio Sotelo; p. 176 a Jerónimo de Aliaga y Pedro Navarro, etc.

14. Cartas privadas de enigrantes a Indias. 1540-1616, Sevilla V Centenario. Consejería de Cultura, Junta de Andalucía, Escuela de Estudios Hispano-Americanos 1988: «as remesas y las llamadas», estudio preliminar de Enrique Otte, ver páginas 25 a 27.

15. Raúl Porras BarrenecheA, op. cit., Tomo I (1529-1534), publicado en 1944, p. 188, Hernando Piçarro: "Para servicio de Francisco Pizarro su hermano, governador del Perú y suyo tiene necesidad de llevar a las Yndias quatro esclavas blancas. Toledo 21 de mayo de 1534".

16. Ver al intelectual peruano Emilio HARTH TERRE, «Esclavas blancas de Lima: 1537», artículo publicado en el diario El Comercio de Lima el 3 de junio de 1963. 
vas blancas, la compra de una esclava blanca hecha por Juan de Vallejo, que ya contaba con concubina india, y la manumisión que otorga López de Idiáquez a favor de Beatriz, tiene mucho que ver con hábitos y costumbres seculares que crearon preferencias, por el tipo y la manera de ser de las moras entre los españoles. Esta disposición para mezclarse con moriscas parece que también la tuvo el Inca Garcilaso de la Vega, durante su larga permanencia en Montilla ${ }^{17}$.

El trabajo del padre Angulo y del doctor Horacio H. Urteaga, destacados historiadores peruanos, ha transcrito testimonios que comprueban la presencia de moriscas, sobre todo en el libro de Partidas de Bautismo de la Parroquia del Sagrario de la Catedral de Lima, en los años 1538 a 1548. La reiterada mención de moriscas y algún morisco como declarantes o como padrinos, la atribuyen a la evidente presencia física mora en el Perú, sobre todo de ellas, que mezclaron su sangre con los conquistadores, quienes las importaban desde España. Las partidas de hijas de españolas en moriscos, que eran esclavas de los hijodalgos avecinados en el Perú, se estima que era el lujo de los ricos encomenderos, que se hacían traer o que compraban esclavas moras ${ }^{18}$. El viajero florentino Francesco Carletti, que visita Lima a fines del siglo XVI, nos deja este testimonio: "En Lima viven muchas nobles familias de caballeros y comerciantes riquísimos que viven con mucha urbanidad y esplendidez mucha mayor que en todas las demás ciudades de las Indias sirviéndose de esclavos moros varones y hembras"19.

Lockhart $^{20}$ nos da otra evidencia: Juana Leyton, morisca esclava que vino al Perú, casó con un italiano que llegó a ser encomendero de Arequipa.

Sin embargo, el mayor éxito estaba reservado a una morisca llamada Beatriz, que llegó al Perú en 1532 como esclava de García de Salcedo, Veedor Real o Controlador. Al año de su llegada recibió su libertad formal. A partir de entonces se comenzó a llamar Beatriz de Salcedo. Como los Oficiales Reales no podían ser mercaderes, ella asumió gran parte de las actividades mercantiles del Veedor. Salcedo se casó con ella ${ }^{21}$. Beatriz se convirtió en una

17. Enrique GARRAMIOLA PRIETO, «El Inca Garcilaso de la Vega, un hombre desengañado», separata del Boletín de la Real Academia de Córdoba de Ciencias, Bellas Letras y Nobles Artes, vol. 125, año LXIV, Córdoba, 1993, p. 111. Reproduce el facsímil de la partida bautismal de Alonso, hijo de Marina, esclava de Garcilaso de la Vega, 27 de marzo de 1570.

18. P. Angulo y Horacio H. URTEAGA, Libro Primero de Babtismos del Archivo del Sagrario, Iglesia Catedral de Lima, 1538-1548, publicado en el Catálogo de la Revista del Archivo General del Perí, Tomo VII, Entrega II, Lima 1929, p. 29. Tomo I, Entrega II, 1937. Tomo XI, Entrega II, 1938. Tomo XII, Entregas I y II, 1939. Tomo XIII, Entregas I y II, 1940. Tomo XIV, Entregas I y II, Lima, 1941.

19. Raúl Porras BarrenecheA, Los viajeros italianos en el Perí, Lima, Editorial Ecos S.A., 1957, p. 49.

20. J. LOCKHART, op. cit., p. 252.

21. Beatriz de Salcedo. Exp. A.G.N. del Perú, Protocolo 127, folios 164 a 169. 
de las más célebres señoras de un prominente oficial y hombre adinerado. El único título que se le negó fue el de Doña. Sus dos hijas casaron bien y, pasados los años, no recordaron sus orígenes. Beatriz reclamaba ser la primera dama española venida al Perú ${ }^{22}$.

Encontramos también un interesante registro histórico sobre el mismo personaje. En la Fundación de Lima, o Ciudad de los Reyes, el 18 de enero de 1535, están presentes muchos personajes, y una sola mujer, Beatriz Salcedo, morisca ${ }^{23}$.

Beatriz no solamente figura en la Fundación de Lima; su presencia la advertimos desde los primeros momentos de la Conquista del Perú. José Antonio del Busto nos dice que, en 1532, Pizarro deja al Veedor Salcedo en la recién fundada San Miguel de Piura, primera ciudad española en el Perú, y que éste se encontraba acompañado por Beatriz su bella esclava morisca. Igualmente cuando el Gobernador funda la primera capital en Jauja, uno de los notables es el Veedor Salcedo, amancebado con Beatriz ${ }^{24}$. De la pasajera unión de la india Inés con Francisco Pizarro nace en 1534 en Jauja, por el mes de diciembre, una niña que recibió en la pila bautismal el nombre de Francisca. Por aquel entonces Jauja era la primera capital de la Gobernación de Pizarro ${ }^{25}$. Con grandes regocijos se festejó el bautizo de la primera mestiza, que sería con el correr del tiempo la mujer más rica del Perú. Para el maduro conquistador, privado del calor familiar, significó un florecimiento de ternura y de afecto. Madrinas fueron Isabel Rodríguez, vecina de Trujillo, Francisca Pinelo, mujer de Rui Barba, y Beatriz "la morisca", mujer del Veedor García Salcedo ${ }^{26}$.

Efraín Trelles ${ }^{27}$ menciona la presencia de otra morisca, llamada igualmente "Beatriz", con quien el encomendero Lucas Martínez de Vegazo tendría hijos.

En la Sección Manuscritos de la Biblioteca Nacional de Perú existe un expediente del Registro de Escrituras Públicas otorgado por el escribano Antón Díaz en 1551 (A-419), que se refiere a un Contrato de Soldada que hacen por un lado Elena de León (morisca) y de otro Andrés de Torres, en

22. Beatriz de Salcedo. A.G.I. Sevilla. Exp. Lima 118, legajo 3840.

23. Ver el artículo del investigador histórico César Miró, «La Plaza Mayor de los Reyes», 17 de enero de 1993, diario El Comercio. Datos tomados de la obra La Fundación de Lima de Juan Bromley, basada a su vez en los Libros de Cabildos de Lima.

24. Ver el historiador peruano José Antonio DEL Busto, Francisco Pizarro, el Marqués Gobernador, Lima, Editorial Brasa S.A. (A. Aviación 2760, San Borja, Lima), 1993 (4a ed.), pp. 87-88.

25. Raúl PorRas BARRENECHEA, «Jauja capital mítica», Revista Histórica. Órgano del Instituto Histórico del Perú, Lima (Empresa Tipográfica Nacional S.A., Restauración 317), tomo XVIII, Entrega II, p. 138 (María Rostowroski reproduce en su obra citada los datos de Porras).

26. Ver nota anterior.

27. Efraín TRelles, Lucas Martínez de Vegazo: funcionamiento de una encomienda peruana inicial, Pontificia Universidad Católica del Perú, 1991, p. 43. 
virtud del Bando que ordenaba que todos los negros, pardos, mulatos, moriscos y berberiscos debían asentarse y servir a un amo ${ }^{28}$.

Una Real Cédula fechada en Palencia el 28 de septiembre de 1534 concede licencia para que Yllán Suárez de Carbajal pueda pasar un esclavo y una esclava blancos que ha criado desde niños, los cuales le conviene llevar a la dicha Provincia del Perú para servicio de su persona y $\operatorname{casa}^{29}$.

Antonio de Calancha ${ }^{30}$ menciona a "Lucía", morisca hechicera que acompañó a Hernández Girón cuando entró a Lima: "hacía creer que tenía revelaciones". Sobre este mismo personaje el Dr. Aurelio Miró Quesada ${ }^{31}$ nos trae la siguiente información: "Cerca de este puente, que antes denominaba de Abancay, el Mariscal Alonso de Alvarado sufrió, en la época bravía de la Conquista y la iniciación del Virreynato, sus dos graves derrotas: la primera, frente a Diego de Almagro el 12 de julio de 1537; y la segunda, en el encuentro con Hernandes Girón, junto a la fortaleza de Chuguinga, el lunes 21 de mayo de 1554. Tremenda derrota y dispersión la de este último combate, que iba a quitar para siempre el reposo al viejo y ardido Mariscal, cuyo destino le había ya anunciado, en una extraña forma, la morisca Lucía de Herrera". "Fue en esta guerra -relata Montesinos- la primera vez que se consultaron hechiceras para los sucesos, pues si bien para las cosas de amor se practican mucho, para las de la guerra sólo Francisco Hernández usó de esas hechicerías".

El Padre Rubén Vargas Ugarte S.J. ${ }^{32}$ transcribe la Carta de Fundación de Capellanía hecha por Malgarida de Almagro, morisca, quien hace una importante donación en retribución a los beneficios recibidos de su señor don Diego de Almagro (El Viejo) quien le había concedido la libertad. Este documento extendido ante escribano está fechado en Lima el 6 de septiembre de 1553.

Debidamente sustentada la presencia de la mujer morisca en la primera época de la Conquista del Perú, estimamos del caso mencionar algunos de sus aportes culturales que han dejado huella en la Historia del Perú. En este recuento de información advertimos que el desarrollo de sus actividades en Indias, que se inician bajo la denominación de "esclava blanca", tiene un

28. Biblioteca Nacional del Perú, Sección Manuscritos, Registro Escrituras Públicas, Escribano Antón Díaz 1551 (A-419): Contrato de soldada en virtud del bando que ordenaba que todos los negros, pardos, mulatos, moriscos y berberiscos debían asentarse y servir a un amo.

29. Raúl Porras Barrenechea, Cedulario del Perú, Tomo II, p. 48, f. 37 v: Concede licencia a Yllán Suárez Carvajal para que pueda pasar un esclavo y una esclava blancos, Palencia 28 de septiembre de 1534.

30. Antonio de la Calancha, Corónica Moralizada, Crónicas del Perú, Edición de Ignacio Prado Pastor, Lima, 1974-1982, 6 volúmenes; vol. II, Libro I, Cap. XXIX, p. 429: "Morisca llamada Lucía, gran echizera, azía creer tenía revelaciones".

31. Aurelio Miro-Quesada Sosa, Costa, Sierra y Montaña, Madrid, Revista de Occidente, 1969, p. 253: "Lucía de Herrera, morisca...".

32. P. Rubén VARGAS UGARTE S.J., historiador peruano, Manuscritos peruanos, Tomo IV, p. 307 , Ref. legajo 9. $\mathrm{N}^{\circ} 252$ de Documentos del Convento de la Merced del Cuzco. 
destino muy diferente al de sus congéneres de condición, mas no de raza. De las labores domésticas pasan a las de administradoras de bienes, consejeras del amo, madre de sus hijos, libertas con un mayor desenvolvimiento en el medio social, para finalmente regresar a España en condiciones ampliamente superadas. Todo este conjunto de hechos determinó que su contribución, a través de diversos aportes culturales, fuese también de mayor aceptabilidad. El ejemplo más evidente lo constituye la moda en el vestir. Según se dice, Lima nace observando el paso gracioso de damas cubiertas, al más típico estilo musulmán, dejando entrever solamente un ojo. Esta moda denominada "tapada" fue criticada en los primeros años del Virreynato. Dícese que el intento de un Virrey por hacer desaparecer esta forma de vestir no tuvo éxito cuando le advirtieron que su propia esposa gustaba vestirse de tapada. Esta vestimenta, que perduró hasta mediados del siglo pasado, se identifica con la ciudad de Lima, pero su origen morisco es preciso reconocerlo.

La cocina es otro renglón importante donde plasmaron su buen gusto. En la variada cocina peruana actual se aprecian rasgos orientales en su preparación y presentación. Ello es más evidente en los dulces y pastelería, que causan admiración a los viajeros árabes por la similitud con sus gustos.

El análisis de estos aportes podría continuar con el folklore, donde pese a las prohibiciones de la Inquisición, se filtraron tonadas y danzas moriscas. También ellas, que actuaron en forma abierta respecto a su identificación de origen, debieron asesorar al artesano morisco o al español, y más tarde al indio, para legarnos tantas expresiones, hasta hoy visibles, en materia de patios, zaguanes, rejas, balcones, adornos, que han perdurado a pesar de que ellas, las inspiradoras, ya no estaban presentes. Las casonas de Lima de los siglos XVI al XVIII conservan elementos propios de una arquitectura islámica que han sorprendido a viajeros europeos que recorrieron el Perú desde 1580 , como es el caso del italiano Carletti. $Y$ en cuanto a las construcciones religiosas, el estilo morisco y mudéjar, lejos de desvanecerse con el tiempo, se acentuaron. Tal es el caso, que llega a oídos de Carlos III esta realidad, que lo induce a firmar una Pragmática mediante la cual recomienda a la Iglesia no dejarse llevar por arquitecturas que nada tienen que ver con nuestra Santa Religión. Una vez más conviene recordar la participación inicial que debió tener la mujer morisca en este campo, donde el aporte propiamente hispánico fue definitivo al haber hecho suyo estos estilos de construcción.

Finalmente cabría señalar que la morisca debió sentirse, sobre todo en la costa peruana, en su hábitat, por un paisaje de desierto y con bellos oasis a los que adornaron trayendo palmeras datileras e inclusive camellos. No es que ellas hiciesen esta importación, pero es muy probable que en su condición de consejeras del hogar y de la administracion que el propio Conquistador les había concedido, tuviesen mucho que ver sus recomendaciones y gustos. En este marco propicio son ellas también las promotoras del mestizaje que hace que hasta hoy en día se conserven rasgos similares a los moros, giros idiomáticos y apellidos. 